\title{
The practice of \\ neuroimaging within a neurology office setting
}

\author{
Joseph V. Fritz, PhD
}

\begin{abstract}
Summary
Imaging is an essential tool in the diagnosis and management of neurologic disorders, yet its adoption in the clinical neurology setting is limited. Perceived cost barriers and political pressures have caused undue apprehension for a community of experts that otherwise plays a leadership role in solving complex neurologic puzzles. Some private practice neurologists have integrated advanced imaging services into a comprehensive neuroservices model, demonstrating its plausibility together with a recipe for success. The purpose of this article is to explore the advantages, disadvantages, and considerations for integrating imaging into an outpatient neurology clinic. Clinical and business advantages are weighed against financial, regulatory, and political risks.
\end{abstract}

I maging plays a substantial role in health care advances aimed at understanding disease processes, early detection, and finding costeffective, targeted therapies. The NIH's Brain Research through Advancing Innovative Neurotechnologies (BRAIN) Initiative seeks to "produce a revolutionary new dynamic picture of the brain." Research and clinical management of devastating neurologic conditions such as traumatic brain injury, dementia, multiple sclerosis (MS), cerebrovascular disease, and neuro-oncology are heavily reliant on imaging. Counterintuitively, neurology has had limited involvement in the practice of neuroimaging.

The changing health care landscape — characterized by declining reimbursement, rising costs, enormous documentation requirements, and seemingly endless regulatory and legal concerns - has been particularly troubling for neurologists. With $63 \%$ of neurologists in private practice, ${ }^{1}$ many are deliberating how to mitigate their risks, improve payer leverage, achieve economy of scale, and maintain autonomy. Mergers and consolidations may transform the neurology landscape into more comprehensive practices. Investment in expensive technology is generally the domain of these larger organizations, which have greater financial stability, management expertise, and volumes of service. As an essential

Dent Neurologic Institute, Amherst, NY.

Funding information and disclosures are provided at the end of the article. Full disclosure form information provided by the author is available with the full text of this article at Neurology.org/cp.

Correspondence to: jfritz@dentinstitute.com 


\section{Cash flow is critical to managing expensive} services. Essentials include prompt billing and collections, advance insurance verification, and intelligent overbooking.

diagnostic tool for neurologists, it is reasonable that such centers consider integrating neuroimaging.

Preston $^{2}$ provides an excellent overview of historical, political, and regulatory issues surrounding the role of neurology in neuroimaging. The primary goal for embarking on this initiative should be to improve service to the community through consistently high-quality, appropriate testing, cost-effectiveness, and superior access. The business needs to be sufficiently strong to withstand market variability and the uncertainties of future payer models. Policies and procedures regarding state and federal regulations must be fully understood and operationalized. Finally, there should be due consideration of the local and national political landscape.

Despite complexity and hurdles, $10 \%$ of neurologists already perform imaging. ${ }^{1} \mathrm{~A}$ simple Internet search reveals many examples of neurology/neuroimaging centers. Table 1 summarizes some of the incentives and disincentives associated with neurologist-owned imaging.

\section{Financial plan}

Determining monetary feasibility is complicated by a breadth of equipment and financing options, and payer model variability and uncertainty. A fictitious MRI purchase analysis is presented to help illustrate the thought process.

Assume each of 8 neurologists in a large group practice can, with the help of nonphysician extenders, accommodate 5 consults and 10 follow-up office visits each day. Given the mix of imaging-intensive subspecialties (eg, TIA, brain tumor, complex headache, MS, and symptomatic back pain patients), 3 to 4 MRIs are ordered per physician daily. They have concluded in-house neuroimaging is warranted to improve clinical decision-making and patient convenience. Assuming no payer restrictions in purchasing or self-referring MRI, could this practice afford an MRI?

The pro forma in table 2 analyzes 2 options using hypothetical 2014 reimbursements from a Midwestern metropolitan area. The average technical component (TC) revenue can be derived from a weighted average of payer fee schedules using practice statistics. The per-scan contribution margin is calculated by subtracting the average variable cost of a scan (e.g., supplies, contrast) from the TC. The product of the contribution margin and the annual billable MRI volume must sufficiently exceed the fixed costs associated with equipment, space rental, and staff. Staffing should initially assume extended hours of operation to maximize capacity, then reduce these costs if warranted by volumes. The calculations indicate that in this payer environment, the approximately 125 scans ordered each week easily justifies a 3T MRI purchase, which requires only 90 patients per week to realize a $5 \%$ profit. A small practice with less patient volume could instead consider a scaled-back operation with lower-cost equipment. The pro forma should also consider that once a strong reputation is built, it is reasonable to expect a fair number of additional neuroimaging and non-neuroimaging referrals directly from outside practices.

Cash flow is critical to managing expensive services. Essentials include prompt billing and collections, advance insurance verification, and intelligent overbooking. Manufacturers will help ease startup through deferred payments, extended warranties, low interest rates, and operating (fair market value buyout) leases. Bank loans are typically required to cover upfront costs. The less compelling a group's financial history, the more any lender will demand personal guarantees. A line of credit or cash on hand equal to a few months of payments is warranted to buffer against outstanding accounts receivable. 
Table 1 Incentives and disincentives for implementing an MRI center

$\begin{array}{ll}\text { Incentives } & \text { Disincentives } \\ \text { Guarantee neuroimaging expertise } & \text { Reimbursement decline } \\ \begin{array}{l}\text { Neuroimagers on the clinic team: improved } \\ \text { understanding, communication, patient relation }\end{array} & \text { Payer uncertainty } \\ \begin{array}{l}\text { Appropriateness better understood and controls } \\ \text { easier to implement }\end{array} & \text { Local relationships tested } \\ \text { Collaborative diagnosis "on the table" } & \text { Risky for small/sole practice } \\ \text { Immediate access to records } & \text { Political antagonism } \\ \text { Patient confidence } & \text { Need for more neuroimaging training } \\ \text { Patient convenience } & \text { programs } \\ \text { Portfolio diversification, group overhead reduction } & \text { Unfamiliar business model } \\ \text { Cost-effective bundled care opportunities } & \\ \text { Participation in neuroscience research } & \end{array}$

\section{Equipment options}

The appropriate MRI platform depends on local needs, demographics, payer constraints, and typical referring diagnoses. The 3T systems leverage advances in diffusion tensor imaging, spectroscopy, susceptibility imaging, and functional MRI, plus higher-resolution imaging, improved angiography, and shorter scan times. Reimbursement is identical to lower field strength MRI services, though there are some offsetting financial advantages in productivity, reputation-induced referrals, and specialty scan reimbursement. Refurbished systems are available at a discount, but upgrades may eventually become costly. Lower field open MRIs are less expensive and offer patient comfort advantages, but it is important to confirm whether local payers have equipment restrictions based on field strength. High-field open MRIs avoid this potential restriction, though the special magnet design comes at a cost premium.

Block leasing is an alternative to full ownership. The lessor acts as the rightful owner during their scheduled time, which must be in explicitly specified blocks for at least 1 year. Lease payments must represent fair market value and cannot be tied to volume. Mobile MRI scanners may be an acceptable variation in sparsely populated geographies where access is limited. These approaches are affordable at much lower monthly volumes, offer a safe startup model, and may open the opportunity for smaller groups to share resources that are otherwise too expensive. Disadvantages include the potential for degradation in the quality of service, payer restrictions regarding split ownerships, and greater regulatory complexity that must be navigated by competent legal advisors.

Other modalities should also be considered in larger and multispecialty practices, including new volumetric CT scanners operating at a very low dose, ultrasound, $\mathrm{x}$-ray/fluoroscopy for arthrography or guided injections, PET/CT, and even PET/MRI for clinical and research functional imaging. The pro forma analysis is similar to the MRI illustration.

\section{Other operational considerations}

Office-based imaging improves patient care only insofar as the service blends seamlessly within a solid neurology practice, together providing fast access, superior customer relationships, and diagnostics that are insightful, accurate, and timely. Indeed, the quality of the neuroimaging physicians and operations will influence referrals more than equipment choice. A poor neurology practice will destroy the imaging business. For example, if it takes months instead of days to obtain a neurology consult, the patient may already have been scanned because the primary care physician and patient are too worried to wait. 
Table 2 Pro forma comparison of fictitious MRI operations

\begin{tabular}{|c|c|c|c|}
\hline & New $3 T$ & 0.3Т Open & Notes \\
\hline \multicolumn{4}{|l|}{ Revenue } \\
\hline Average global reimbursement & $\$ 450$ & $\$ 450$ & Payer mix and bad debt \\
\hline Technical component & $\$ 360$ & $\$ 360$ & \\
\hline \multicolumn{4}{|l|}{ Variable expenses } \\
\hline Billing ( $5 \%$ of gross receipts) & $\$ 22$ & $\$ 22$ & \\
\hline Office supplies & $\$ 2$ & $\$ 2$ & \\
\hline Transcription per report & $\$ 6$ & $\$ 6$ & \\
\hline Technical margin per scan & $\$ 319$ & $\$ 319$ & \\
\hline Reception, clerical (3T: 2 FTE, Open: 1) & $\$ 60,000$ & $\$ 30,000$ & \\
\hline 1.0 FTE Manager, IT support & $\$ 90,000$ & $\$ 90,000$ & \\
\hline \multicolumn{4}{|l|}{ Annual fixed expenses } \\
\hline Equipment operating lease & $\$ 460,555$ & $\$ 222,778$ & $\$ 1.8$ million vs $\$ 750,000,5$ y FMV \\
\hline MRI service contract & $\$ 144,000$ & $\$ 100,000$ & \\
\hline Rent & $\$ 105,000$ & $\$ 105,000$ & $(\$ 35 / s f \times 3,000 \mathrm{sf})$ \\
\hline Installation cost & $\$ 113,227$ & $\$ 113,227$ & (\$500,000, 5 y loan @ 5\%) \\
\hline PACS/RIS & $\$ 98,155$ & $\$ 98,155$ & (\$375,000, 5 y FMV @ 5\%) \\
\hline Total fixed expenses & $\$ 1,362,937$ & $\$ 926,160$ & \\
\hline Desired return on investment & $5 \%$ & $5 \%$ & \\
\hline Desired revenue from operations & $\$ 1,431,084$ & $\$ 972,468$ & \\
\hline \multicolumn{4}{|l|}{ Required number of scans } \\
\hline Per year & 4,487 & 3,049 & Revenue/margin \\
\hline Per week & 90 & 61 & \\
\hline
\end{tabular}

Abbreviations: FTE = full-time equivalent; PACS = picture archiving and communication system; RIS = radiology information system.

Quality is attained by investment in talent, training, and management. Technologists must be specially trained in neuroimaging to ensure consistent image quality, able to identify pathology sufficiently well to alert physicians while the patient is on the table, optimize the scan protocol for the patient's condition, and be able to respond knowledgeably to patient questions, symptoms, and emergencies. The physicians who oversee imaging should have a thorough understanding of the referring diagnosis, allowing them to play an important role in appropriateness verification, physician and staff education, and scan protocolling. Images and expert interpretations must be readily available for the decision-making physician. Notification 


\section{Office-based imaging improves patient care only insofar as the service blends seamlessly within a solid neurology practice, together providing fast access, superior customer relationships, and diagnostics that are insightful, accurate, and timely.}

of critical results must be immediate and preferably through direct interaction between the imager and clinician.

Small practices may find it difficult to manage or justify costly expansion into imaging. Merging with other specialists having similar cultures and ancillary referral patterns —including neurologists, neurosurgeons, and orthopedists — overcomes these hurdles, and is a practical alternative to facing the increasing burden of health care regulation alone.

\section{Physician interpretation}

Clinical neurologists often find themselves developing care plans based on their interpretation of images rather than relying on the radiology report. Sometimes the report is not available or lacks clinical insight, or simply because neurologists ultimately responsible for treatment decisions place more trust their own neurology training. That someone else, and not the neurologist, gets paid for the reporting can be a source of frustration. One of the driving forces to integrating imaging into a neurology practice is to improve this disconnect.

Choices for imaging interpretation include employed or contracted general radiologists, neuroradiologists, or fellowship-trained neurologists. Using general radiologists is inconsistent with the goals of a neuroimaging program. The better strategy is to fully embrace neuroscience expertise, starting with staff neuroimagers who bring a combination of neurology and imaging training, fully appreciate the relationship between clinical indications and identified pathology, are expert at on-the-fly protocol optimization based on presenting neurologic conditions, and oversee departmental communication, education, feedback, and outcomes research.

Neurologists with fellowship training in imaging who maintain some clinical practice are a natural fit for a neuroimaging operation. Concern about additional liability for nonradiologist interpretations has not surfaced in our practice, in which neuroimagers and neuroradiologists have interpreted hundreds of thousands of cases for almost 30 years without incident. Non-neurologic studies or incidental findings are forwarded to radiologists for their interpretation, and neuroradiologists participate in a systematic peer review process. The cost of malpractice insurance for imaging neurologists is no different than for diagnostic neuroradiologists.

Both neuroradiologists and fellowship-trained neurologists are in short supply. This has fueled renewed interest in neuroimaging training for neurologists, as well as improved clinical and specialty training for radiologists. ${ }^{3,4}$ Several organizations are working with the Association of University Professors of Neurology, seeking to improve imaging education and remove barriers to training during residency. The American Academy of Neurology (AAN) Imaging Section offers regular education through the Continuum Series and the AAN annual conference. The American Society of Neuroimaging (ASN), formed by neurologists in 1977, comprises neurologists, neuroradiologists, neurosurgeons, and scientists from private practices, industry, and academia interested in a clinical collaborative approach to neuroimaging education and science. Its annual meeting and Journal of Neuroimaging have evolved into an important source of neuroimaging training. The United Council of Neurologic Subspecialties 
accredits neuroimaging fellowship programs and has certified 140 neuroimaging diplomats since 2008, when the first subspecialty of neuroimaging examination was given.

\section{Payer issues and regulations}

Imaging centers must be accredited through the American College of Radiology (ACR), the Intersocietal Accreditation Commission, or the Joint Commission in order to submit claims. Each mandates well-maintained equipment, credentialed technologists, documented policies and procedures based on national guidelines, qualified physician oversight, and logs for training and critical events. Any on-site staff physician may supervise technologists and nurses for contrast injections or sedation. Only general supervision is required for a nurse practitioner to administer contrast. The medical director and reading physicians need to meet standards set forth by the accrediting organization. Radiologists who maintain their continuing medical education credits are automatically certified, while nonradiologists must document competency through training and supervised experience.

Insurance companies are sensitive to rising costs, and suspicious that self-referring groups will fill schedules due to financial pressures rather than clinical need, and often require additional preauthorization. An active relationship with payers is extremely helpful in developing and monitoring appropriateness metrics, and can play a valuable role in driving physician behavior that assures the practice maintains value to the payer. Payer assessment of physician quality and cost is increasingly using grouper software that ties diagnosis and procedure codes to episodes of care. ${ }^{5}$ Physician scores influence financial penalties or incentives, affect reputation, and may result in disqualification. Internal auditing programs should use similar scoring methodologies, and provide education and feedback regarding appropriateness based on ACR and AAN guidelines.

The Stark Law, also known as the In-Office Ancillary Service Exemption (IOASE), governs self-referral. Among a myriad of requirements, the profit distributions to owner physicians cannot be tied to referral volume, and physician services must be provided at the scanner site, minimally 30 hours per week. Patients must be informed that the practice has ownership interest and provided a list of alternative imaging centers. Other potential restrictions exist at the federal, state, and payer level. Antimarkup rules enforce fair market payment to any contracted interpreting physicians. The Anti-Kickback Law and Federal False Claims Act protect against direct or indirect means of incentivizing referrals.

Many resources are available to stay apprised of evolving self-referral and imaging issues (table 3), including government updates through Twitter and e-mail. Societies such as the Medical Group Management Association provide timely and complete education surrounding health care regulation. Ultimately, a competent attorney is essential to ensuring compliance with evolving regulations.

\section{National policy trends}

Self-referral has been the subject of intense, polarizing national debates. Most recently, a 2012 study by the US Government Accountability Office (GAO) concluded that self-referral increases the cost of medicine by $\$ 109$ million per year. ${ }^{6}$ The Centers for Medicare and Medicaid Services subsequently stated it would consider appropriateness controls in the medical review strategy for advanced imaging services.

A follow-up analysis by the American Society of Neuroimaging showed the GAO neglected to recognize the cost-shifting and cost-savings effect of outpatient comprehensive care, thereby propagating a dangerous misperception that masks the positive role neurology can play in health care savings. ${ }^{7}$ The GAO data itself show that while the proportion of self-referred imaging between 2007 and 2010 indeed grew from 19\% of the outpatient market to 23\%, the total cost of all outpatient imaging was essentially flat. One explanation is that rather than practicing defensive medicine, referring physicians defer to specialists, if available and trusted, to judiciously order the proper tests instead. The self-referring neurology practice will therefore absorb and minimize a community worth of imaging, but as a result will appear to be a 
Table 3 Useful resources

\begin{tabular}{|c|c|c|}
\hline & Offerings & Internet addresses \\
\hline American Academy of Neurology & $\begin{array}{l}\text { Practice support, guidelines, continuum } \\
\text { education, BRAINS }\end{array}$ & www.aan.com \\
\hline $\begin{array}{l}\text { Medical Group Management } \\
\text { Association }\end{array}$ & $\begin{array}{l}\text { Practice management guidelines, } \\
\text { regulatory updates }\end{array}$ & www.mgma.com \\
\hline $\begin{array}{l}\text { Centers for Medicare and } \\
\text { Medicaid Services }\end{array}$ & $\begin{array}{l}\text { Government policy updates: blogs, } \\
\text { tweets, and listservs }\end{array}$ & $\begin{array}{l}\text { www.cms.gov, www.cms.gov/Medicare/Fraud- } \\
\text { and-Abuse/PhysicianSelfReferral/index.html, } \\
\text { www.twitter.com/CMSGov, www.cms.gov/ } \\
\text { About-CMS/Agency-Information/Aboutwebsite/ } \\
\text { Email-Updates-List.html }\end{array}$ \\
\hline $\begin{array}{l}\text { Intersocietal Accreditation } \\
\text { Commission }\end{array}$ & Accrediting body & www.intersocietal.org \\
\hline Joint Commission & Accrediting body & www.jointcommision.org \\
\hline Cave Group Consulting & Episode grouper software & www.cavegroup.com \\
\hline Aunt Minnie & Imaging business news & www.auntminnie.com \\
\hline $\begin{array}{l}\text { Coalition for Patient Centered } \\
\text { Imaging }\end{array}$ & $\begin{array}{l}\text { Represents physician societies dedicated } \\
\text { to high-quality imaging }\end{array}$ & AAN (www.aan.com) and other society web sites \\
\hline Imaging industry & Equipment advice & Philips, Siemens, GE, Toshiba, Hitachi.com \\
\hline
\end{tabular}

higher utilizer (table 4), even though the imaging is appropriate. ${ }^{8}$ The GAO study curiously ignores potential savings achieved by avoiding hospital imaging, which is typically much more expensive and represents $77 \%$ of advanced imaging costs.

Nevertheless, President Obama's 2014 budget proposal acknowledged the GAO analysis and "encourages more appropriate use of ancillary services by only allowing providers who meet certain accountability standards to self-refer." On May 17, 2013, the Congressional Budget Office released its impact study of the President's health care proposals, and associated the line item "Excluding certain services from the In-Office Ancillary Services Exception (IOASE)" with a $\$ 1.8$ billion savings over 10 years. ${ }^{10}$ Left unchallenged, it is possible that poor policy decisions will be made.

The threat of IOASE repeal cannot be ignored when constructing expansion strategies. However, the Consortium for Patient-Centered Imaging collectively represents a wide range of affected specialties and is actively advocating for more rational reforms. Assuming clear heads prevail, there will likely be continued movement toward implementing decision support systems and invoking financial rewards and penalties associated with episode-of-care metrics.

\section{DISCUSSION}

Neurology practices that operate imaging as part of an accessible, comprehensive neuroscience program offer financial and quality value to the community while benefiting from economy of scale that improves the group's viability and sustainability. Compared to many neurologists who are straining to keep up and lose $60 \%$ or more of their professional revenue to overhead, these practices can apply ancillary profits to offset clinic costs, operate at a fraction of typical 


\section{Table 4 Illustration of how GAO calculations can misrepresent cost-shifting and cost savings due to self-referral of imaging}

\begin{tabular}{|c|c|c|c|c|c|c|c|c|c|}
\hline & \multirow[b]{2}{*}{ Cost } & \multicolumn{3}{|c|}{ Defensive medicine practice } & \multicolumn{3}{|c|}{ Expert neuroimaging practice } & \multicolumn{2}{|c|}{$\begin{array}{l}\text { Perceived IOASE- } \\
\text { related excess vs peers }\end{array}$} \\
\hline & & $\begin{array}{l}\text { PCP- } \\
\text { ordered } \\
\text { MRls }\end{array}$ & $\begin{array}{l}\text { MRIs by } \\
\text { neurologist } \\
\text { unavailable for } \\
\text { timely consult }\end{array}$ & Cost & $\begin{array}{l}\text { Neurologist- } \\
\text { ordered } \\
\text { MRIs }\end{array}$ & Cost & $\begin{array}{l}\text { Actual } \\
\text { savings }\end{array}$ & $\begin{array}{l}\text { Excess } \\
\text { scans? }\end{array}$ & $\begin{array}{l}\text { Excess } \\
\text { cost? }\end{array}$ \\
\hline Outpatient scans @ & $\$ 500$ & 18 & 0 & $\$ 9,000$ & 10 & $\$ 5,000$ & $\$ 4,000$ & 10 & $\$ 5,000$ \\
\hline Hospital scans @ & $\$ 750$ & 2 & 0 & $\$ 1,500$ & 0 & $\$-$ & $\$ 1,500$ & & \\
\hline Total & & 20 & 0 & $\$ 10,500$ & 10 & & $\$ 5,500$ & 10 & $\$ 5,000$ \\
\hline
\end{tabular}

group professional overhead rates, attract better talent, build a more service-oriented infrastructure, participate in research, and generally create a much more exciting climate. Neurologists interested in billing for imaging interpretation can receive training through the ASN or other professional organizations. Small practices may get started in imaging using less expensive equipment options, but should strongly consider merging into larger, more comprehensive and financially viable practices.

Health care reform adds investment risk, necessitating conservative fiscal and contingency planning. The most likely reform will involve appropriateness safeguards, with organizations such as the AAN working closely with payers and government to ensure fair representation of the neurologist's value. Active participation in education and negotiation with payers, societies, local politicians, and media is essential to fair recognition of the neurologist's role in imaging.

Despite a projected shortage of neurologists, they remain among the least paid physicians and lowest residency fill rate. Development of comprehensive neuroscience settings offers an achievable path toward reversing this trend. At a time when imaging is at the heart of important new national brain research initiatives, it would be ill-considered to find neurologists unable to participate at a mainstream level.

\section{REFERENCES}

1. Adornato BT, Drogan O, Thoresen P, et al. The practice of neurology, 2000-2010: report of the AAN Member Research Subcommittee. Neurology 2011;77:1921-1928.

2. Preston WG. Neuroimaging practice issues for the neurologist. Semin Neurol 2008;28:590-597.

3. Atlas SW. Embracing subspecialization: the key to the survival of radiology. J Am Coll Radiol 2007;4: 752-753.

4. Ruiz JA, Glazer GM. The state of radiology in 2006: very high spatial resolution but no visibility. Radiology 2006;241:11-16.

5. Ellis P, Sandy LG, Larson AJ, et al. Wide variation in episode costs within a commercially insured population highlights potential to improve the efficiency of care. Health Aff 2012;31:2084-2093.

6. Government Accountability Office. Higher Use of Advanced Imaging Services by Providers Who SelfRefer Costing Medicare Millions: 2012. Available at: http:/www.gao.gov/assets/650/648988.pdf. Accessed April 13, 2013.

7. Hutchinson M, Rowe E. Yet another flawed study of self-referral? AJR Am J Roentgenol 2012;199: W414.

8. Hutchinson M, Rowe E, Kushner M, et al. Appropriate use of advanced imaging services by providers who self-Refer is saving medicare billions. J Neuroimaging 2013;23:159-161.

9. US Government Printing Office. Fiscal Year 2014 Budget of the US Government, 2013, Office of Management and Budget. Available at: http://www.whitehouse.gov/sites/default/files/omb/budget/ fy2014/assets/budget.pdf, pp 40-41. Accessed April 12, 2013. 
10. Congressional Budget Office. Estimated Effects on Direct Spending and Revenues for Health Care Programs of Proposals in the President's 2014 Budget: 2013. Available at: http://www.cbo.gov/ publication/44247. Accessed April 13, 2013.

\section{ACKNOWLEDGMENT}

The author thanks the members of the American Society of Neuroimaging for their review of the manuscript and comments.

\section{STUDY FUNDING}

No targeted funding reported.

\section{DISCLOSURES}

J. Fritz is a full-time employee of the Dent Neurologic Institute, a private neurology group practice that self-refers imaging, is a Board of Directors member of the American Society of Neuroimaging, and has received travel and speaker honoraria from the American Academy of Neurology. Full disclosure form information provided by the author is available with the full text of this article at Neurology.org/cp.

\section{Related articles from other AAN physician and patient resources}

\section{Neurology ${ }^{\circledR} \quad \bullet \quad$ www.neurology.org}

Invited Article: Functional imaging in Parkinson disease April 15, 2008;70:1478-1488.

Practical approaches to incidental findings in brain imaging research January 29, 2008;70:384-390.

\section{Continuum ${ }^{\circledR} \quad$ - www.ContinuumJournal.com}

Neuroimaging in Investigation of Patients With Epilepsy June 2013;623-642.

Incorporating New Diagnostic Schemas, Genetics, and Proteinopathy into the Evaluation of Frontotemporal Degeneration

April 2013:438-456.

Neurocysticercosis

December 2012:1392-1416.

\section{Neurology Now ${ }^{\circledR} \quad$ www.neurologynow.com}

Searching for the Early Signs of Alzheimer's Disease October/November 2012;8:34-35.

New Imaging Captures the Brain's Complexity May/June 2010;6:9-10.

\section{Neurology Today ${ }^{\circledR}$}

- www.neurotodayonline.com

NEWS FROM THE AAN ANNUAL MEETING: Abeta, Brain Volume, and Dementia: Why New Imaging Findings Present a Complicated Prognostic Picture May 16, 2013;13:17-18.

A New Generation of Neuroimaging Technologies: New Insights into Pathology of Brain Disorders May 17, 2012;12:22-23. 